\title{
Is herbicide resistance an undissolute problem?
}

\author{
Leonardo Bianco de Carvalho
}

Recently, Weed Science journal published a special issue on weed resistance to herbicides (Weed Science, Volume 64, 2016), regarding many issues on the importance and the impact of the weed resistance on agronomic and social aspects. This brief note regards topics covered by some authors.

Sarah Ward wrote about the human dimensions of herbicide resistance (WARD 2016). She said "herbicide resistance has become a major topic of international research in weed science, with a steady stream of presentations and papers on various aspects of the biology of herbicide resistant weeds". According to her, several sources indicate recommendations for preventing and managing herbicide resistance, however the problem continues to increase in field conditions. She explains a part of this problem occurs due to an insufficient attention to "the human component of herbicide resistance evolution and management".

David R. Shaw implied herbicide resistance has no clear causes or solutions, and thus it is "difficult or impossible to solve", becoming a "wicked problem" (SHAW 2016) for everyone involved in herbicide use. He emphasized "if we expect to achieve success in herbicide resistance management, different approaches will be essential", culminating in "a call to action for everyone involved in the decision-making process". In addition, Raymond A. Jussaume Jr. and David Ervin stated that "finding farm management approaches that help farmers successfully address weed resistance requires a shared perspective that incorporates an improved understanding of the human dimensions of weed management" (JUSSAUME JR. \& ERVIN 2016). So, bringing together the ideas of SHAW (2016) and JUSSAUME JR. \& ERVIN (2016), educational programs, technical assistance, diversification of weed management, regulatory efforts, and other strategies should be used to play significant roles in constructing management approaches for herbicide resistance.

Terrance M. Hurley and George Frisvold indicated herbicide-resistance management must overlap economic barriers to be effective and sustainable (HURLEY \& FRISVOLD 2016). They said the act of weed management, guided by humans, drives the biological-evolutionary process of selecting herbicide-resistant weeds; and thus "the problem is socioeconomic as well as biological". So, they concluded that breaking the economic barriers "requires an adaptive approach that transitions from more-uniform and costly standards and incentives, which can be effective in the near-term but, are unsustainable when compared to more-targeted and less-costly approaches that are sustainable in the long term.

Harold D. Coble and Jill Schroeder idealized that the "management of herbicide resistance can be most effectively accomplished if every person and organization involved in agricultural production takes an ownership position and participates in solving the growing problem of weed resistance to herbicides" (COBLE \& SCHROEDER 2016). They indicated that "growers and other pest management practitioners are key to effective herbicide resistance management", but "many other people and organizations have an important role to play as well". They concluded that "it is critically important that all of these groups impacting herbicide resistance management decisions are sending the same message and that message is based on sound science".

In conclusion, efforts must be made by all people involved in any process of plant production (food, fiber, etc.) whereby weeds are being controlled by using herbicides. If joint efforts are not performed, the problem of herbicide resistance will continue increasing.

\section{REFERENCES}

COBLE HD \& SCHROEDER J. 2016. Call to action on herbicide resistance management. Weed Science 64: 661-666. JUSSAUME JR. RA \& ERVIN D. 2016. Understanding weed resistance as a wicked problem to improve weed management decisions. Weed Science 64: 559-569.

Universidade Estadual Paulista, Jaboticabal, SP, Brasil.

*Author for correspondence <lbcarvalho@fcav.unesp.br> 
HURLEY TM \& FRISVOLD G. 2016. Economic barriers to herbicide-resistance management. Weed Science 64: 585594.

SHAW DR. 2016. The "wicked" nature of the herbicide resistance problem. Weed Science 64: 552-558.

WARD S. 2016. Human dimensions of herbicide resistance. Weed Science 64: 551-551. 